\title{
Maintenance and Transformation of Problematic Self-Narratives: A Semiotic-Dialogical Approach
}

\author{
António P. Ribeiro • Miguel M. Gonçalves
}

(C) Springer Science+Business Media, LLC 2010

\begin{abstract}
This study focuses on how the emergence of innovative moments (IMs), which are exceptions to a person's dominant self-narrative (i.e., his or her usual way of understanding and experiencing), progresses to the construction of a new self-narrative. IMs challenge a person's current framework of understanding and experiencing, generating uncertainty. When uncertainty is excessively threatening, a semiotic strategy to deal with it often emerges: attenuation of novelty's meanings and implications by a quick return to the dominant self-narrative. From a dialogical perspective, a dominant voice (which organizes one's current self-narrative) and a non-dominant or innovative voice (expressed during IMs) establish a cyclical relation, mutual in-feeding, blocking self-development. In this article, we analyze a successful psychotherapeutic case focusing on how the relation between dominant and non-dominant voices evolves from mutual in-feeding to other forms of dialogical relation. We have identified two processes: (1) escalation of the innovative voice(s) thereby inhibiting the dominant voice and (2) dominant and innovative voices negotiating and engaging in joint action.
\end{abstract}

Keywords Innovative moments $\cdot$ Dialogical self $\cdot$ Mutual in-feeding $\cdot$ Semiotic regulation

We have been developing a research program (see Gonçalves et al. 2010c for a review) that addresses human change processes in psychotherapy and in everyday life by tracking the way novelties emerge in former patterns of acting, feeling, thinking and relating. We consider these exceptions- which we call innovative moments (IMs; also named as i-moments in previous publications) $)^{1}-$ as new

\footnotetext{
${ }^{1}$ Previous research has consistently shown that IMs can be reliably identified by use of the Innovative Moments Coding System (IMCS; Gonçalves et al. 2010a, b), and that they occur in psychotherapeutic change in different models of brief therapy (Gonçalves et al. 2010c). Furthermore, research suggests that there are five different categories of IMs which correspond to different narrative processes: action, reflection, protest, reconceptualization and performing change. From these studies our research team developed a heuristic model of change (see Gonçalves et al. 2010c).
}

A. P. Ribeiro • M. M. Gonçalves $(\bowtie)$

School of Psychology, University of Minho, 4710 Braga, Portugal

e-mail: mgoncalves@psi.uminho.pt 
emergent meanings that have the latent power to promote change (Gonçalves et al. 2009). As we will see below, after the emergence of an IM one possible path of development is the amplification of the IM's meaning, which precipitates new IMs and eventually leads to a significant change in the former pattern. When this process is developing uncertainty may be a by-product of the change that is occurring, since the person is now facing an unfamiliar pattern of acting, relating, feeling and so on. Thus, when change occurs a discontinuity has to be resolved. In this paper we elaborate on how the process of restoration of continuity that follows an IM-a potential opportunity for development to occur - may end up promoting stability and blocking self-development. We agree with Stiles (1999, p.1), when he claims that psychotherapy offers "a more intimate access to human experience than does almost any other arena"; thus from psychotherapy research we aim to deepen our understanding of how meanings are transformed or, conversely, remain stable.

\section{Self-Narratives and the Dialogical Self}

Every narrative has some narrator who is telling a story to an audience (Salgado and Gonçalves 2007). Thus, every meaning construction involves an addressee: "The I emerges by reference with an Other" (Salgado and Hermans 2005, p. 10). Consequently, at each moment the person assumes a semiotic position (see also Leiman 2002) toward the world and toward others. In other words, the person responds to the lived situation and each and every utterance or thought has this dialogical basis. Therefore, life becomes a dance of constant repositioning from moment to moment. These several positions, called I-positions within the Dialogical Self Theory (DST; Hermans 2001; Hermans and Hermans-Konopka 2010), may then animate inner and outer dialogues, in which several "voices" can be heard.

According to DST, multivocality means that self-narratives, besides their temporal organization, also have a spatial dimension (see Hermans and Hermans-Jansen 1995), resulting from the possibility that the self has metaphorically to move from one position to the other, giving voice to different authors and producing different narratives of the events. That is, for the same topic or event, different voices can emerge, representing different positions of the self. Thus, as Hermans (e.g., Hermans and Dimaggio 2004) has suggested, the self is similar to a community of voices, making the interpersonal processes that occur between people equivalent to the intrapersonal processes. Consequently, self-narratives are the outcome of dialogical processes of negotiation, tension, disagreement, alliance and so on between different voices of the self (Hermans and Hermans-Jansen 1995).

\section{Problematic Self-Narratives}

When a dominant community of voices is bound together by a self-narrative that is too rigid and systematically excludes significant experiences because they are not congruent with it, people become vulnerable to distress (Gonçalves et al. 2010d). Along with Stiles (Stiles 2002; Stiles et al. 2004), we suggest that from the dominant community's perspective voices representing experiences that are different from how 
a person typically perceives him or herself are problematic, and the community of voices wards off, distorts, or actively avoids such voices. Although such avoidance can prevent or reduce distress in the short term, the experiences remain unassimilated and unavailable as resources. From a clinician's perspective the exclusion of non-dominant voices represents a form of narrative dominance (Neimeyer et al. 2006). Narrative dominance is problematic given that it produces a high redundancy in the way the person attributes meaning to experience. Of course, not all forms of dominance are problematic. On the contrary, dominance is a common pattern in everyday life, responsible for people taking a position, assuming a certain perspective (e.g., political), or even involving themselves in meaningful actions. We refer here to a form of dominance in which the person is telling the same self-narrative over and over again, independently of the circumstances. Clinical depression can be seen as a good prototype of this. No matter how events change, the same (depressiogenic) interpretation is repeated over and over again (see Beck 1976).

\section{Innovative Moments}

Problematic dominance involves a form of monologization of the self, in which the difference is rejected or denied. For instance, the depressiogenic interpretation of reality is maintained by a denial of alternative formulations, marginalizing other voices. As Bakhtin (1981) suggested, however, the attempt to suppress the other (external or internalized) is never completely achieved (Goncalves and Guilfoyle 2006; Salgado and Gonçalves 2007; Valsiner 2004). Accordingly, Stiles (e.g., Stiles et al. 2004) suggests that unassimilated voices are not inert or devoid of agency. They may be silenced and excluded, but circumstances (including the therapeutic dialog) may address them, compelling them to move to the foreground. When this occurs IMs emerge, and the dominance of the previous self-narrative is disrupted. Dialogically, then, IMs are opportunities for unassimilated voices to emerge and to tell their own stories, which differ from the ones told by the dominant community.

We have been developing a methodological tool that allows tracking of IMs in psychotherapy and everyday life, trying to understand how a new, more flexible, self-narrative is constructed-the innovative moments coding system (IMCS; Gonçalves et al. 2010a, b). It is important to note that although our method is inspired in a narrative framework, it tracks micro-narratives, not, self-narratives. These micro-narratives are not full-fledged narratives since they do not meet the usual criteria for what constitutes a complete narrative, as required by narrative theorists (e.g., Mandler 1984) but they could be part of more molar narrative structures.

\section{Protonarratives}

In the development of the problematic self-narrative into an alternative one, IMs with several different meanings start to occur. In the course of change, IMs tend to become organized in clusters of themes. We have called such recurrent meanings or themes protonarratives (Ribeiro et al. 2010a, b). Protonarratives are noticeable as recurrent 
themes that differ from the ones present in the dominant self-narrative. Protonarratives are not yet self-narratives because of their provisional nature, but they can develop into a self-narrative throughout the therapeutic process, which justifies the prefix proto. We have suggested that, in successful therapy, the alternative self-narrative develops as a sequence of protonarratives, which are successively revised and refined in the light of continuing experience (Ribeiro et al. 2010a, b).

\section{Innovative Moments as Bifurcation Points}

The emergence of IMs and corresponding protonarratives generates uncertainty, since the individual has to face a discontinuity that challenges his or her usual framework of understanding (Ribeiro and Gonçalves 2010). When this discontinuity is highly accentuated it could trigger a felt sense of contradiction or self-discrepancy, thus creating dysphoric feelings of unpredictability and uncontrollability (Arkowitz and Engle 2007). From a dialogical perspective, a non-dominant (or innovative) voice strives to gain power, challenging the dominant one (s), leading the dialogical self to rearrange or modify its configuration until it finds relative stability, i.e., restores continuity.

IMs can thus be construed as a microgenetic bifurcation point (Valsiner and Sato 2006), in which the client has to resolve uncertainty, i.e., the tension between two opposing voices - one expressed in the dominant self-narrative (e.g., submissive) and another expressed in the emerging IM (e.g., assertive) - drawing upon semiotic strategies such as attenuation or amplification (Valsiner 2008). Semiotic attenuation refers to the minimization, depreciation or trivialization of a particular meaning present in an IM, resulting in the maintenance of the old patterns (Fig. 1). Conversely, semiotic amplification refers to the expansion of a given meaning present in an IM, creating an opportunity for development to occur. For instance, an IM can be amplified by means of therapist interventions

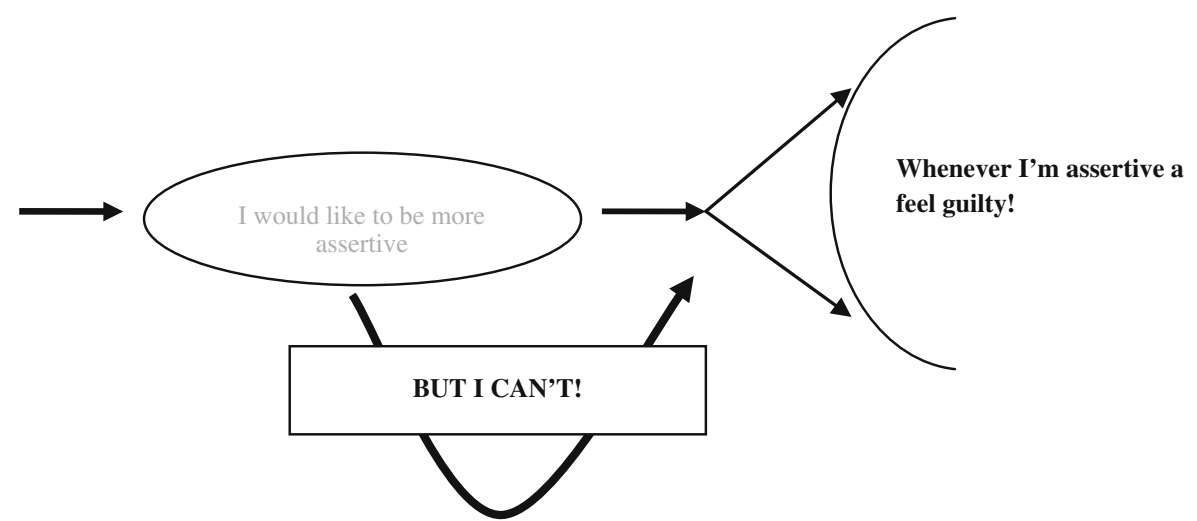

Fig. 1 Semiotic attenuation. From "Constraining one's self within the fluid social worlds," by Valsiner 2008. Adapted with permission 


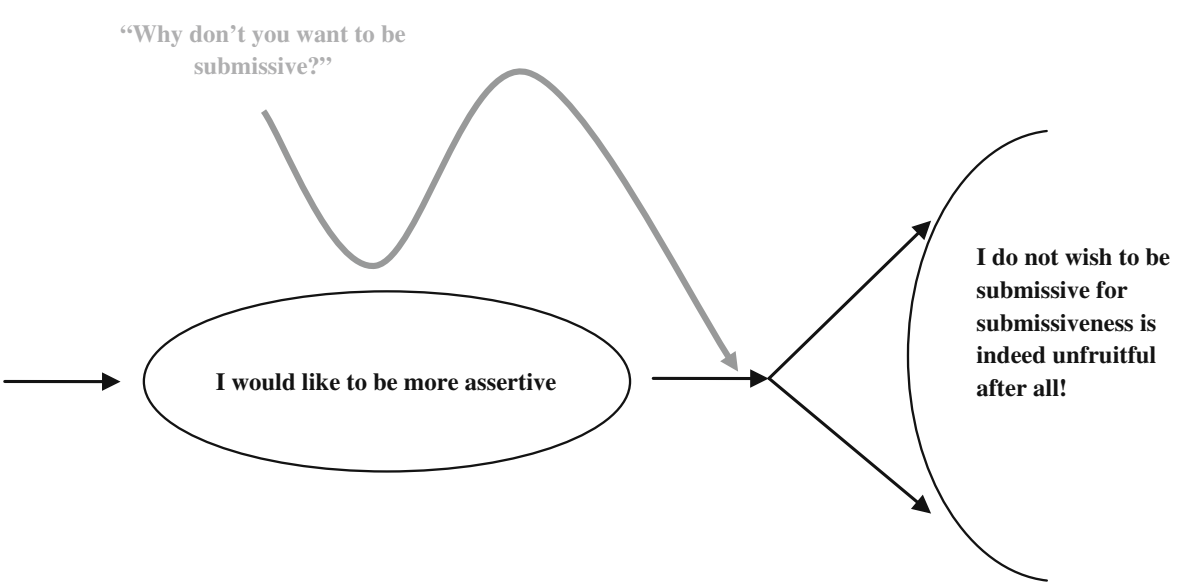

Fig. 2 Semiotic amplification. From "Constraining one's self within the fluid social worlds," by Valsiner 2008. Adapted with permission

that catalyze further elaboration of a particular IM (e.g., "Why don't you want to be submissive?") or enhance its meaning ("So, what would your life be like if you were more assertive") (Fig. 2).

The way uncertainty is resolved at each IM regulates and is regulated by the dialogical relations between the dominant voice(s) expressed in the dominant selfnarrative and the innovative voice(s) expressed in IMs, as well as in the therapist's interventions (Gonçalves and Ribeiro 2010) (Fig. 3). Development is fostered if the innovative voice (the one that is narrating the IM) is given priority, by semiotic amplification ultimately producing a new self-narrative. On the other hand, if the meaning of IMs is recurrently attenuated, the innovative voice stays dominated, and the problematic self-narrative maintains or even reinforces its power.

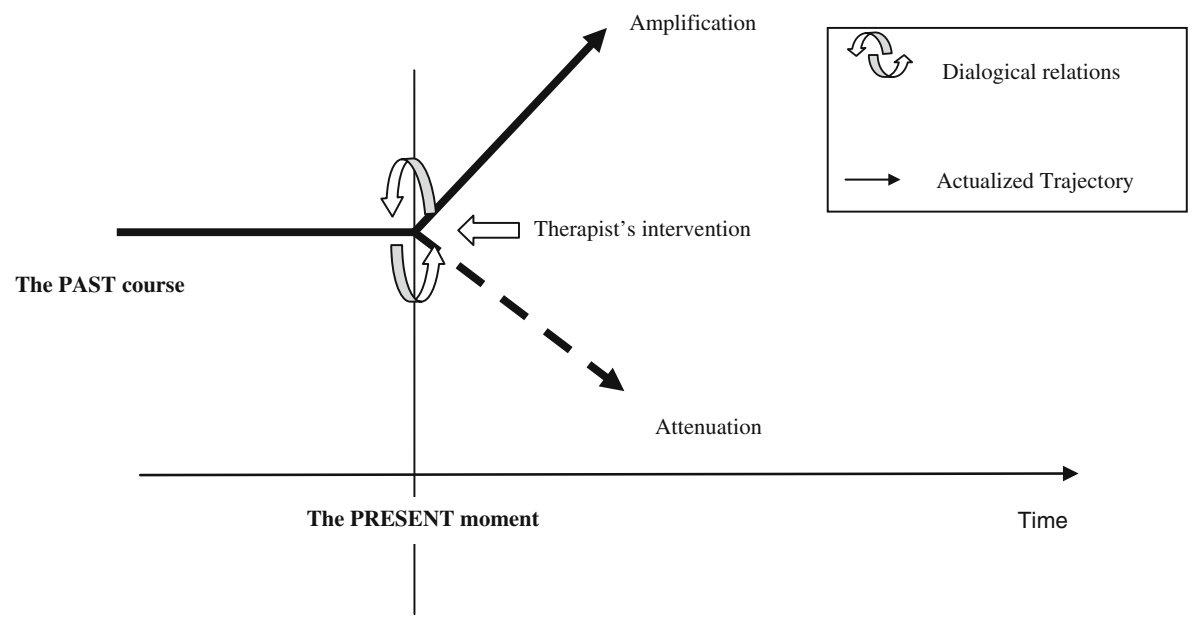

Fig. 3 IMs as bifurcation points. From "Depicting the Dynamics of Living the Life: The Trajectory Equifinality Model", by Sato et al. 2009. Adapted with permission 


\section{The Role of Mutual In-feeding in Maintaining Problematic Self-Narratives}

Frequently in unsuccessful psychotherapy cases (Santos et al. 2010), as well as in initial and middle phases of successful ones (Ribeiro et al. 2009), clients tend to resolve the uncertainty created by the emergence of an IM by attenuating its meaning, making a quick return to the dominant self-narrative. This may result in the disappearance of a particular innovative way of feeling, thinking, or acting, reinforcing the power of the dominant self-narrative and thus promoting self-stability.

Dialogically, a new voice (or a previously non-dominant one) has its change potential aborted by the reaffirmation of the dominant voice. By doing this, clients temporarily avoid discontinuity but do not overcome it as the non-dominant voice continues active and thus IMs emerge recurrently. As Gonçalves and Ribeiro (2010, p.12) have stated:

In some cases this struggle between the dominant self-narrative and the IMs keeps going on, during the entire psychotherapeutic process. We have here two opposing wishes (expressed by two opposing voices): to keep the self stable, avoiding discontinuity and the uncertainty generated by it; and to change, avoiding the suffering which the dominant self-narrative most of the times implies. When novelty emerges, the person resolves the problem of discontinuity by returning to the dominant narrative. When the client feels too oppressed by the dominant self-narrative he or she resolves this problem by trying to produce novelty, but of course this poses the problem of discontinuity once again. Thus, the self is trapped in this cyclical relation, making ambivalence impossible to overcome within this form itself.

The process described above mirrors a form of stability within the self, in which two opposite voices keep feeding each other, dominating the self alternatively, that Valsiner (2002) has termed mutual in-feeding. Mutual in-feeding allows the maintenance of the dominant self-narrative, despite the emergence of novelties.

\section{Observing Mutual In-feeding}

We have proposed a measure of the mutual in-feeding process that grew from our observations of therapy passages in which an IM emerged and is immediately followed by a return to the dominant experience. We call such events a return-to-theproblem marker (RPM). For example:

"I don't want to be submissive anymore (reflection IM), but I just can't" (RPM).

In this example, the client described an IM- "I don't want to be submissive anymore" - and then returned to the dominant self-narrative by saying "but I can't." This clause, introduced by the word but, represents opposition or negation towards the innovative voice and hence constitutes the RPM.

The results obtained in a sample of narrative therapy with women who were victims of intimate violence showed that IMs were much more likely to be followed by a return to the dominant self-narrative in unsuccessful cases than in successful ones (Gonçalves et al. 2010d). Although mutual in-feeding is more characteristic of 
unsuccessful psychotherapy, it is also present in successful cases. In what follows we will analyze IMs' emergence in a successful psychotherapeutic case, focusing on the semiotic processes that regulate the dialogical relations between the dominant voice(s) present in the dominant self-narrative and the non-dominant voices present in IMs. We have been studying these micro-processes using the microgenetic method ${ }^{2}$ from a semiotic-dialogical perspective (Valsiner 2004; see also Josephs et al. 1999). In the following section, we elaborate on Josephs and colleagues' (1999; Josephs and Valsiner 1998) dialogical-dialectical approach to meaning-making and apply this framework in the context of a theory-building case study (Stiles 2005, 2009).

\section{Meaning-Making: A Dialogical-Dialectical Approach}

According to Josephs and colleagues (1999; Josephs and Valsiner 1998) the construction of meaning entails the regulation of dialogical relations between signs, construed as meaning complexes composed of dual fields: the field $\{\mathrm{A}\}$ and $\{$ non $A\}$. The field non-A operates as negativum in relation to A (see Josephs et al. 1999). These dual fields emerge together (explicitly or implicitly), being $\{A\}$ the sign and $\{$ non $A\}$ the countersign of $\{A\}$, as in $\{A\}$ the foreground and \{non $A\}$ the background. For instance, if $\{\mathrm{A}\}$ is worthlessness, it is associated also with a whole range of its opposites - happiness, hopefulness, confidence, etc.- defined by the field \{non A\}, composing both the meaning complex \{worthlessness and non-worthlessness\}. The meaning of worthlessness is intrinsically dependent on the meaning of its opposites.

The field $\{\mathrm{A}\}$ is composed of a sign or signs with a specific meaning, to which we can relate synonyms and various versions by using semantic qualifiers (cf. Josephs and Valsiner 1998). Qualifiers usually modify the meaning of the field, either opening it to transformation or closing it. Therefore, the meaning of the field $\{\mathrm{A}\}$ could be opened up for transformation by the use of qualifiers, which are signs that limit or modify the meaning of the field, such as "sometimes" or "all the time." For instance, "I feel a bit worthless sometimes" is different from "I see myself as a rather negativistic sort of person these days, always thinking the worst..." The latter entails a sense of totality of the person's life and actually closes the meaning complex to transformation. The non A f field emerges together with the previous $\{A\}$, although in an unstructured or fuzzy way. The relation between $\{\mathrm{A}\}$ and non $\mathrm{A}\}$ can be tensional or harmonious. When both opposites co-occur with no tension at all, they tend to close the meaning complex. On the other hand, if tension occurs it enables the complex to transform, as it allows the establishment of dialogical relations with other meaning complexes.

On the one hand, meaning transformation can occur through a process of growth of the $\{\mathrm{A}-$ worthlessness $\}$ field. It can become progressively differentiated into $\{A$ - defeated $\},\{A "$-impotent $\}$ or $\left\{A^{\prime \prime}\right.$-negativistic $\}$, and so on. In these transformations, the similarity to the $\{A\}$ field is maintained. On the other hand, meaning transformation can occur through a process of constructive elaboration of the $\{$ non A $\}$ field. For instance, in the example "I feel a bit worthless sometimes"

\footnotetext{
${ }^{2}$ Microgenetic analysis is a method for studying how change develops in a certain period of time in a given individual. It involves intensive analysis of the transformation mechanisms and it has been widely applied in developmental studies of children (Flynn et al. 2007; Siegler and Crowley 1991).
} 
$(\{\mathrm{A}\})$, the word "sometimes" (a semantic qualifier) highlights that there are times in which the speaker does not feel worthless. Hence, we can assume that the word "sometimes" corresponds to an elaboration of the field \{non A\} (that is, there are times when the person does not feel worthless). This elaboration on $\{$ non A $\}$ increases the tension between the field $\{\mathrm{A}$ : feeling worthless\} and the implicit opposite field \{non A: not feeling worthless $\}$, fostering the emergence of a new meaning complex $(\{B\})$ that establishes a dialogical relation with the first one. For instance, this new field $(\{B\})$ could be "I've been feeling more cheerful these last few days."

To sum up, we can consider, for the purpose of this work, the field $\{\mathrm{A}\}$ as the meaning complex that organizes the dominant voice and $\{$ non $\mathrm{A}\}$ as the whole range of oppositions related to it. In therapeutic conversation, if the client chooses to elaborate on the field \{non A\}, either voluntarily or at the therapist's suggestion, it is most likely to lead to the development of a novelty, or to an IM, as some version of $\{$ non $A\}$. The elaboration of the field \{non A\} can lead to another meaning field $\{\mathrm{B}\}$, originating the meaning complex $\{\mathrm{B}<>$ non $\mathrm{B}\}$. We also assume that the field $\{$ non $B\}$ could entail features of the field $\{A\}$. For instance, if $\{A\}$ is worthlessness and $\{B\}$ worthiness, $\{$ non $B\}$ could entail meanings of $\{A\}$. Thus, through the insertion of $\{\mathrm{B}<>$ non $\mathrm{B}\}$, a relation is established between the new meaning complex present in IMs and the previous complex present in the dominant self-narrative, which leads to a contrast of the two meaning complexes. This contrast can take different forms depending on how the individual regulates the $[\{\mathrm{A}<>$ non $\mathrm{A}\} \quad\{\mathrm{B}<>$ non $\mathrm{B}\}]$ relationship.

Meaning-making entails the regulation of dialogical relations between meaning complexes, $\{\mathrm{A}\}$ and $\{\mathrm{B}\}$. They can have dialogical relations of two different natures: harmonious or tensional. In harmonious coexistence, $\{A\}$ and $\{B\}$ can coexist without rivalry:

"That's how I feel-weak, invariably sad, not thinking much of myself..." [ $\{\mathrm{A}\}]$ and "It's not what I do at work or at school, because I believe I have some kind of value" $[\{B\}]$.

In the previous example the coexistence between $\{\mathrm{A}\}$ and $\{\mathrm{B}\}$ is clear as they cooccur without any sort of tension. When tension is present some kind of resolution is needed:

"Sometimes, with my boyfriend...I still let some things go by, because, well, I am still afraid of being that pain-in-the-neck sort of person, always insisting on this and that. Sometimes I still find it difficult to realize whether what I am thinking should be discussed with him or not, I remain in the twilight of doubt, obscurity, is it really? Is it really not? $[\{\mathrm{A}\}]$ "but the truth is that I try to lead our relationship in a softer, easier way $[\{\mathrm{B}\}]$."

In this example, the use of the word "sometimes" underscores that the statement "I still let some things go by" ( $\{\mathrm{A}\})$ is valid only for a specific moment. Then a new meaning is elaborated $\{B$ : "I try to lead our relationship in a softer, easier way" $\}$. We can assume that the person resolved the tension between \{A:"I still let some things go by" $\}$ and $\{\mathrm{B}$ : "I try to lead our relationship in a softer, easier way" $\}$ by using the expression "the truth is" to insure that pessimism did not interfere. Therefore, the tension was resolved by the takeover of $\{\mathrm{A}$-worthlessness $\}$. 
As in the previous excerpt, people regulate the relations between meanings complexes by means of circumvention strategies (Josephs and Valsiner 1998; Josephs et al. 1999). They are semiotic tools used by people instantly in the task of organizing the flow of everyday experience. They can strengthen a given meaning, resulting in semiotic amplification, or overcome it, resulting in semiotic attenuation. Their role is to give meanings a marginal or central importance, engendering their maintenance or change. Circumvention strategies can act in a number of ways (see Josephs and Valsiner 1998 for further elaboration). In what follows, we describe two circumvention strategies that we found useful for understanding dialogical processes involved in IMs attenuation and amplification:

1. Circumvention of meaning by focusing on a competing goal and/or highlighting personal preferences - the person bypasses a given meaning as he or she highlights a motivational goal that rivals the previous meaning (e.g., "[I see myself as a rather negativistic sort of person these days], [but] I want to improve! I want to go back to my old good self!").

2. Circumventing of meaning by means of focusing on semantic qualifiersexpressions that somehow emphasize an absolutist and determinist fashion in IMs, such as "I truly believe things are on the right track, I do feel a lot better" can be used, but others that seem to promote some instability in meaning can also be used, like "I feel a bit worthless sometimes," which can open the meaning to further elaboration.

\section{Case of Caroline}

\section{Client}

Caroline was a 20-year-old White female who gave permission for her materials to be used for research. She reported as her main problems feelings of sadness, hopelessness and worthlessness, following her entrance to university and the beginning of a romantic relationship, which impaired her interpersonal relationships and her academic functioning. She described difficulties with being assertive (especially with her boyfriend), satisfying the needs of others to the detriment of her own needs. She usually took responsibility for her parents' problems, trying to protect her mother from her father, who used to stalk her even after divorce. During therapy, Caroline was able to make connections between these different problems and realize how they were all part of a larger functioning pattern: pessimism.

Caroline was diagnosed with an adaptation disorder with depressive symptoms, according to DSM IV (American Psychiatric Association 1994). Her case was considered a good-outcome case on the basis of significant symptomatic change evidenced in the pre-post Outcome Questionnaire ${ }^{3}$ total score (OQ-45.2; Lambert et

\footnotetext{
3 The Outcome Questionnaire (OQ) is a brief self-report instrument, composed of 45 items, designed for repeated measurement of client status through the course of therapy and at termination. It monitors the client's progress in three dimensions: subjective discomfort, interpersonal relationships and social role functioning. A Portuguese version was developed by Machado, Machado and Klein (2006). The internal consistency values for the OQ-45 Total and respective subscales were in satisfactory ranges (0.69 to 0.92).
} 
al. 1996; Portuguese version adapted by Machado and Klein 2006). Her pre-therapy OQ-45 total score of 99 dropped to 50 at therapy termination. A Reliable Change Index (RCI) analysis of her OQ-45 pre- to post-test change scores classified Caroline as having met criteria for recovery (i.e., passed both a OQ-45 cut-off score of 67.82 and RCI criteria; Machado and Fassnacht 2010) at treatment termination (see Jacobson and Truax 1991; McGlinchey et al. 2002).

This case was previously coded for IMs, RPMs and protonarratives by Ribeiro and colleagues (Ribeiro et al. 2009, 2010b).

\section{Therapy and Therapist}

Caroline was seen in brief and individual constructivist therapy ${ }^{4}$ focused on implicative dilemmas (Fernandes 2007; Fernandes et al. 2009; Senra et al. 2007) for 12 sessions and one follow-up session, at her university's clinic. Therapy terminated by mutual decision after completion of the treatment manual, as therapist and client agreed that the main goals had been achieved. Video and audio recordings were made of all 12 sessions. Sessions 1 and 11 were not recorded owing to technical problems, leaving ten sessions available for our analysis.

The therapist was a 25-year-old White female doctoral student of clinical psychology, with 3 years of prior clinical experience as psychotherapist, who had undergone training in the therapeutic model prior to the therapeutic intervention and attended weekly group supervision for this case.

\section{Analytical Strategy}

Data for the current study were drawn from the Ribeiro et al.'s (2009) study of IMs and RPMs in constructivist therapy and Ribeiro et al. (2010b) study of protonarratives in constructivist therapy. Relevant parts of those studies' method and results are summarized here; please see Ribeiro et al. (2009) and (2010b) for full details. Our research strategy involved four major steps of analysis: (1) identifying IMs (previously carried out by Ribeiro et al. 2009); (2) identifying RPMs (previously carried out by Ribeiro et al. 2009); (3) identifying protonarratives (previously carried out by Ribeiro et al. 2010b); and (4) depicting the processes by which the protonarratives emerged and evolved throughout therapy and their relation with mutual in-feeding.

\footnotetext{
${ }^{4}$ According to Senra and Ribeiro (2009), "Implicative dilemmas represent a form of blockage in the individual's constructing activity, where an undesired construction is strongly related to other, positive and self-defining, construction(s). As a result, the person can't move towards a desired construction as that would imply abandoning some nuclear features of the self, or embracing some undesired aspects that correlate with the wanted one" (p.1). Senra et al. (2007; see also Fernandes 2007) developed a brief therapy aimed at solving these impasses in the clients' constructions organized in five stages: (1) assessment, (2) reframing the problem as a dilemma, (3) dilemma elaboration, (4) alternative enactment and (5) treatment termination. Sessions are structured in terms of goals and tasks, but there is time flexibility for their completion. Their proposal adopts a hermeneutic and phenomenological perspective, using predominantly explorative interventions, privileging reflection and elaboration of the client's personal meanings.
} 
Identifying Innovative Moments: Coding Procedures and Reliability Session recordings were coded according to the IMCS (Gonçalves et al. 2010a, b) by three judges: Judge 1 coded all the sessions available (10 sessions); and Judges 2 and 3 (who were unaware of the outcomes) independently coded five sessions each. Before beginning their independent coding of IMs, the judges discussed their understanding of the client's problems (dominant self-narrative). This step was guided by the question: "What is the central rule/framework that organizes Caroline's suffering?" This discussion aimed to generate a consensual definition of the client's main selfnarrative rules so that the exceptions to the rules (IMs) could be coded. Caroline's problematic self-narrative was characterized as the "pessimism" rule, that is, the idea that no matter what efforts she made she would never achieve positive results, and that she was not worthy. Consider the following:

Caroline: I see myself as a rather negativistic sort of person these days, always thinking the worst, and I don't trust myself that much (...) I feel gloomy and not wishing to socialize with anyone (...) I don't see myself as willing or ready to face conquest, I feel myself impotent to fight against or whichever for, unable to go and search what I need (...) I feel kind of defeated, with no muscle to fight (...) I feel rather low (...) For instance, haven't got the slightest wish ever to undertake some sort of physical activity that I like (...) I know that I'll be worrying with something else or I'll be feeling that deep anguish, that uneasiness I see myself in, with my mind sort of frozen, blocked, and I won't be able to do other things (...) There's something inside me that prevents me from moving forward, have guts, feel the power (...) Last Saturday, for instance, I did nothing, absolutely no-thing, I was either in the Internet talking with Rachel (a friend), or who-whatever came by, I wanted to put the computer aside and study and I just couldn't!

This self-narrative is highly contaminated by intense sadness, hopelessness and worthlessness. Keeping the pessimism rule in mind, judges coded IMs from video and audio recordings, identifying each IM's onset and offset to the nearest second. We computed the total percentage of time in the session devoted to IMs (we termed this measure IM salience). The percentage of agreement on overall IM salience was $84.1 \%$. Because of the high inter-judge reliability, we based our analyses on Judge 1 's coding.

Identifying Return-to-the-Problem Markers: Coding Procedures and Reliability Two judges participated in the RPM coding procedure. RPMs coding comprised two sequential steps: a) independent coding; and b) resolving disagreements through consensus. The judges independently coded the entire sample (10 sessions), analyzing previously coded IMs regarding the presence of RPMs. The sessions were coded from video and audio recording in the order in which they occurred. Reliability of identifying RPMs, assessed by Cohen's Kappa, was .93, based on the initial independent coding.

Identifying Caroline's Protonarratives: Coding Procedures and Reliability Coding protonarratives involved a discussion between the first author and a team that ranged from 2 to 12 researchers, along with an auditing process (Hill et al. 2005). This step 
was guided by the question: "What is the potential counter-rule/framework of behaving (acts, thoughts, emotions) present in this IM?" or in a different but equivalent formulation: "If this IM expands itself to a new self-narrative, what would be the rule that shapes this new self-narrative?" The authors tried to capture the answer to this question in the form of a sentence or a word. The protonarrative for each successive IM was then compared with the protonarratives previously described, to look for convergences and divergences. Whenever strong convergences were found, the new IM was understood as sharing the previously described protonarrative. When strong divergences were found, a new protonarrative was formulated to incorporate the new meanings.

The salience of each protonarrative was computed for each session as the sum of the salience of IMs in which they emerged. The mean salience of each protonarrative throughout the process was also computed.

Depicting the Processes by Which the Protonarratives Emerged and Evolved Throughout Therapy and Their Relation with Mutual In-feeding We adopted Josephs and collaborators' dialogical-dialectical approach to meaning-making (Josephs and Valsiner 1998; Josephs et al. 1999; see also Santos and Gonçalves 2009) to understand how IMs emerge, how they remain captive in the process of mutual in-feeding and also how they develop into a successful outcome (resolving mutual in-feeding).

\section{Results and Discussion}

IMs and RPMs Across Therapy

In Fig. 4 we have represented the evolution of percentage of time in the session occupied by IMs — which we term salience - and the percentage of IMs with RPMs. In this case, IM salience presented an increasing trend, while IM with RPM has a decreasing one. The percentage of IMs with RPMs was very high until the third session, decreasing afterwards, but remaining above 30\% until session 9 (see Ribeiro et al. 2009).

\section{Protonarratives Across Therapy}

After an in-depth analysis of Caroline's IMs, Ribeiro et al. (2010a, b, c) identified three protonarratives summarized in Table 1: optimism (Mean salience $=15.77 \%$ ), achievement $($ Mean salience $=4.29 \%$ ) and balance (Mean salience=6.98\%). As shown in Fig. 5, sessions differed with respect to the presence of protonarratives. Sessions 2 and 3 were characterized by only occasional instances of \{Optimism\} exclusively. In session 4 \{ptimism\} and Achievement\} were present and in session 5 only \{Optimism\} was present again. In sessions 6 and 7 the three protonarratives were present. In sessions 8 and 9 two protonarratives were present again: \{Optimism\} and \{Achievement\} in session 8 and \{Achievement\} and \{Balance\} in session 9. Sessions 10 and 12 were characterized by the presence of the three protonarratives again 
Fig. 4 IM Salience and percentage of IMs with RPMs across therapy

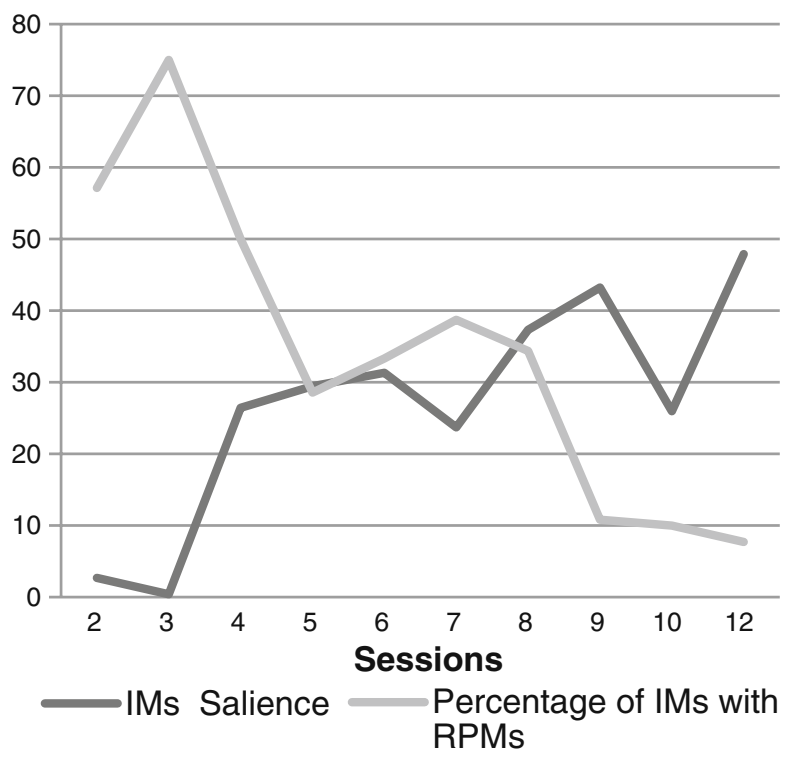

Protonarratives and Mutual In-feeding

Figure 6 plots three variables: protonarratives (axis x), RPMs (axis y), and the salience of each IM (represented by size of circles). Placement of the circles within the cells is arbitrary; circles are arranged to allow representation of successive events of the same type, using computer software: the Gridware (Lamey et al. 2004).

As shown in Fig. 6, the three protonarratives showed different likelihoods of including RPMs. The first protonarratives to emerge, \{Optimism $\}$ and $\{$ Achievement\}, presented a higher percentage of IMs with RPMs $(29.1 \%$ and $33.8 \%$ respectively) than $\{$ Balance\}, which was the last to emerge $(10.7 \%)$.

Protonarratives Emergence and Mutual In-feeding Maintenance and Transformation

In what follows, we will shed light on the microgenetic semiotic-dialogical processes by which these protonarratives emerged and evolved throughout the therapy and their relation to mutual in-feeding maintenance and transformation.

Optimism: Mutual In-feeding Between Dominant and Innovative Voice(s) IMs focused on \{Optimism\} were mostly centered on considerations about the capacities Caroline had in the past and also on her self-capacity to achieve change. This content is the exact opposite of what Caroline defined as the "pessimism" rule, that is, the idea that whatever she did she would never achieve positive results, and that she was not worthy. Let us look at the following excerpt:

Second session

Caroline: Maybe because I felt inclined to impose myself targets all my life and do my utmost to achieve them, always with a lot of hard work, but I 
Table 1 Protonarratives in Caroline's case

\begin{tabular}{ll}
\hline Protonarratives & Contents \\
\hline$\{$ Optimism $\}$ & - Life areas and/or capacities not dominated by pessimism \\
& - Intention to overcome pessimism \\
& - Comprehension of pessimism causes \\
& - Awareness of pessimism effects \\
& - Strategies implemented to overcome pessimism \\
$\{$ Achievement & - Well-being \\
& - Balanced relationship between pessimism and optimism \\
& - Balanced relationship between own needs and other's needs \\
& - Balanced relationship between study/work and leisure
\end{tabular}

From "Dynamic Look at Narrative Change in Psychotherapy: A Case-Study Tracking Innovative Moments and Protonarratives Using State-Space Grids", by Ribeiro et al. 2010b. Adapted with permission

always managed to get there somehow... [emergence of an IM \{Optimism $\}$ ] and nowadays... I realize I don't have that strength any longer [RPM\{Pessimism\}-IM's attenuation]. Maybe I'll get what I want after all, I don't know ... [emergence of an IM \{Optimism\}] but I feel weak, psychologically speaking ... like me or someone inside me was incessantly saying you cannot, you will not be able to do it. That's how I feel-weak, invariably sad, not thinking much of myself... [RPM-\{Pessimism $\}-$ IM's attenuation].

In this excerpt, first Caroline emphasized her self-worth, enacting an IM\{Optimism: "Maybe because I felt inclined to impose myself targets all my life and do my utmost to achieve them $\}$." She employed the past tense, however, relegating her capacities to the past. Also, the field \{Optimism\} is followed by considerations about the difficulties she had in achieving her goals - "always with a lot of hard work" - which are an expression of the field \{non-Optimism\}, with characteristics easily identified with \{Pessimism\}. The elaboration of the \{non-Optimism field\} seems to have fostered the re-emergence of the $\{$ Pessimism $\}$ field as she soon

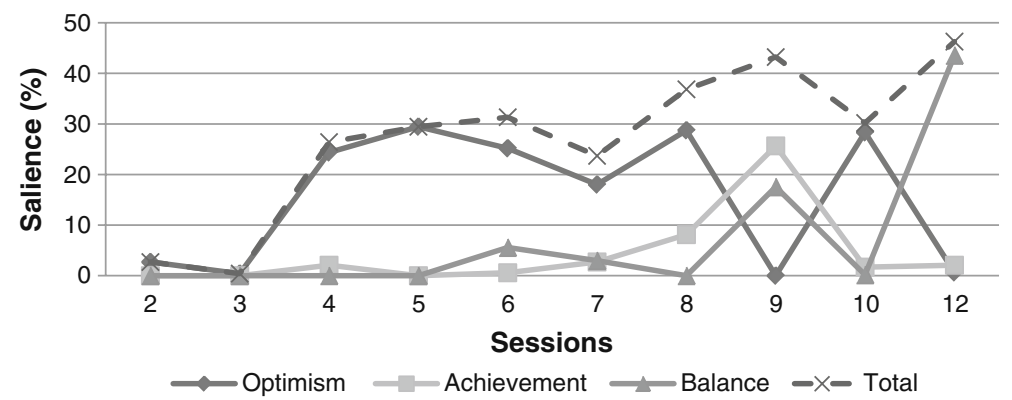

Fig. 5 Protonarrative salience across therapy. From "Dynamic Look at Narrative Change in Psychotherapy: A Case-Study Tracking Innovative Moments and Protonarratives Using State-Space Grids", by Ribeiro et al. 2010b. Adapted with permission 
Fig. 6 Protonarratives and RPMs

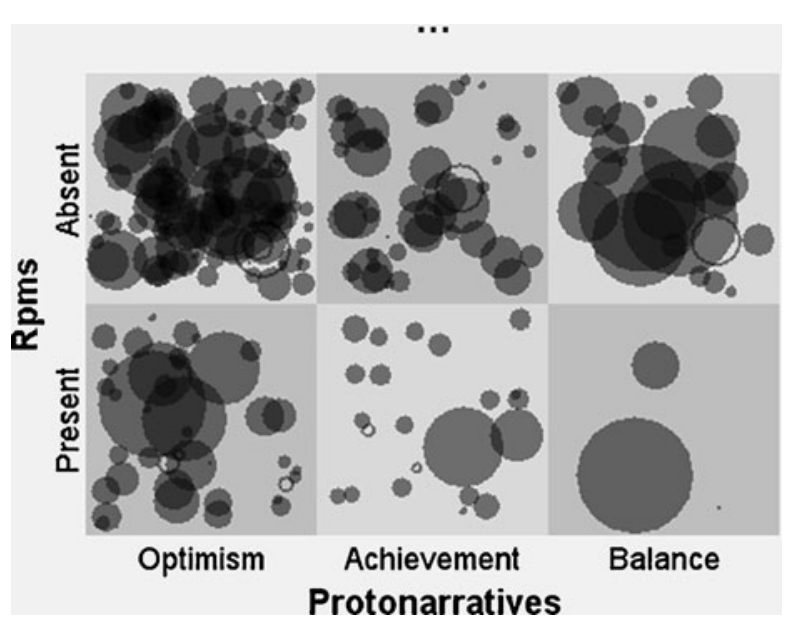

returns to the problem when she says \{“... and nowadays... I realize I don't have that strength any longer\}." By doing so, she attenuated the meaning of the previous IM.

After that, Caroline elaborated another IM \{Optimism: "Maybe I'll get what I want after all, I don't know $\}$." Yet, the expression "I don't know" can be conceptualized as a $\{$ non-Optimism $\}$ being rather close to the $\{$ Pessimism $\}$ meaning complex, once it stresses that the IM's meaning was not structured enough (also denoted by the word "maybe"). Although a new meaning complex ("Maybe I'll get what I want after all, I don't know") was brought into therapeutic conversation, its potential for development was immediately bypassed. In this sense, Caroline actually returned to and strengthened the meaning of the dominant meaning complex, despite the emergence of the IM, as she said \{Pessimism: "but I feel weak, psychologically speaking ... like me or someone inside me was incessantly saying you cannot, you will not be able to do it. That's how I feel—weak, invariably sad, not thinking much of myself' $\}$. This meaning complex was clearly related to (or even expressed by) the dominant self-narrative. The employment of the words "invariably" and "incessantly" (i.e., semantic qualifiers) showed how definite and determinist this organizer had been in Caroline's life. This is a circumvention strategy for taking over the "I'll get what I want" statement, expressing "you cannot, you will not be able to do it" and thus attenuating the IM's meaning (see Fig. 7).

These excerpts enabled us to see a repetitive pattern in IM emergence at the beginning of therapy. They were often a mere opposition to the problem, which without considering specific strategies that could be catalytic of change, made the return to the problem - and thus the attenuation of IM meaning - also predictable (Santos et al. 2010).

In the analyzed excerpts, the meanings present in IMs were frequently followed and consequently attenuated by the dominant self-narrative. It seemed that IMs were systematically trivialized, neglected or simply taken over by the immediate emergence of the $\{$ Pessimism $\}$. So, dialogical relations of opposition and rivalry between the $\{$ Pessimism $\}$ and the $\{$ Optimism $\}$ were "solved" by an immediate return to the problem - attenuation. The high frequency of IMs focused on \{Optimism\} with RPMs seemingly mirrors a dynamic stability between the dominant voice(s) and the 


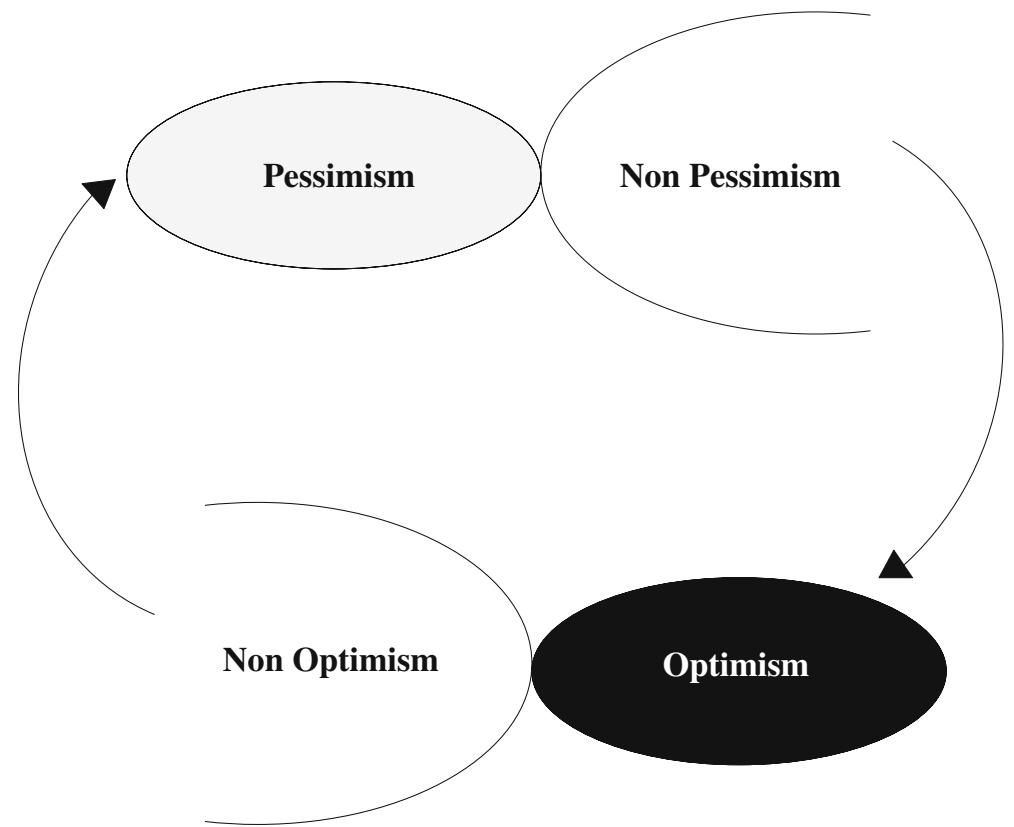

Fig. 7 A dialectical understanding of mutual in-feeding. From "The Process Of Meaning ConstructionDissecting The Flow Of Semiotic Activity”, by Josephs et al. 1999. Adapted with permission

innovative one(s), in which they relate in a way that feed each other, in a mutual infeeding process. The opposing voices seemed "to fight for possession of the floor" (Brinegar et al. 2006, p.170). This self-contradictory speech, in which innovative meanings seemed to trigger contradictory dominant meanings, and vice versa, is akin to what Stiles and collaborators call Rapid Cross Fire (e.g., Brinegar et al. 2006).

In this sense, IMs did not evolve to the construction of other possible voices, as they were absorbed into the vicious cycle (see Fig. 8). Innovative voice(s) seemed to work as a shadow of the dominant voice(s) (Gustafson 1992), allowing its perpetuation and closing down the meanings system. This process ended by strengthening the dominant voice(s) and maintaining its dominance not only because it was still present, but because it prevented other possible voices from developing.

The asymmetric rigidified stability that characterizes the dialogical relationships between the dominant voice(s) and the innovative ones in the initial phase was progressively surpassed throughout the treatment. In the following sections, we illustrate how the emergence of $\{$ Achievement\} and $\{$ Balance $\}$ protonarratives helped to transform mutual in-feeding into a different dialogical modality.

Achievement: Escalation of the Innovative Voice(s), Thereby Inhibiting the Dominant Voice(s) Achievement emerged for the first time in the fourth session. Its content reveals a more empowered relation to the problem, as we can observe in the following example:

Fourth session

Caroline: ... I'd very much like to get there, particularly now with my studies. [emergence of an IM- $-\{$ Optimism $\}$ ]. I'm in the 2 nd grade of the degree $X$ and getting to the end is sounding quite an unachievable goal [RPM $\{$ Pessimism $\}$, 


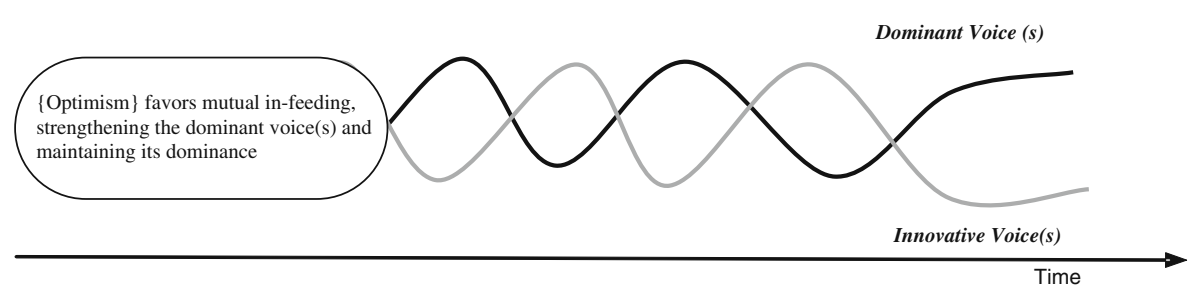

Fig. 8 Mutual in-feeding

I'd like to... [emergence of an IM-\{Optimism $\}$ ].

Therapist: We need to change things here, exactly at this point, you say you haven't been able to ... get some sort of stability in order to be able to... [Therapist elaborates on \{non-Pessimism\}, catalyzing the amplification of the previous IMs].

Caroline: To get going because [emergence of an IM-\{Optimism $\}$, well, I don't give up, you see, I keep on studying and realizing what my needs are... this week, for instance, I was rather quiet, managed to study [emergence of an IM-\{Achievement $\}$ ] (...)At least I know I did study, I read [emergence of an IM-\{Achievement $\}]$... This week I felt a bit more, well, a bit more loose [emergence of an IM- Achievement $\}$ ].

The previous example has two IMs with different content. Initially, Caroline enacts an IM acknowledging that she wanted to change (\{Optimism\}). This IM was then circumvented by a personal competing goal "is sounding quite an unachievable goal"-attenuation. Nevertheless, Caroline soon bypassed this meaning (that supports the problem), by focusing on self-preferences, as she said "...I'd like to..." The therapist explored this window of opportunity, by elaborating on nnonPessimism\}, which seems to have fostered the elaboration in \{Optimism\}amplifying the previous IM-, and then the emergence of \{Achievement\}. Indeed, Caroline acknowledged the therapist's meaning "get some sort of stability in order to be able to" by saying "To get going," from where she enacted another IM ("This week I felt a bit more, well, a bit more loose"), as she stated an actual change of starting to feel better.

Caroline seemed to be able to identify a set of new self-capacities, grounded in specific actions \{Achievement: "I did study, I read"\}, that are not limited to the dichotomy pessimism vs. optimism. The emergence of \{Achievement\}, that encompasses both actions (e.g., "I did study, I read"), implemented to defy the problem, and reflections about the change process (e.g., "This week I felt a bit more, well, a bit more loose") seem to have taken over both $\{$ Pessimism $\}$ and $\{$ Optimism\} fields. The neutralization of these fields appears to play a pivotal role in surpassing mutual in-feeding and opening the opportunity to the emergence of new selfmeanings that are not by their nature close to the $\{$ Pessimism $\}$ meaning.

This process seemingly promotes an escalation of the innovative voice(s), which may inhibit the power of the dominant one(s) (see Fig. 9). Hermans (1996a, b) has characterized this process as a form of dominance reversal: the position that was once dominant is now dominated. The dominance reversal in this case is temporary, given that IMs focused on \{Achievement\} still present a considerable number of RPMs. 


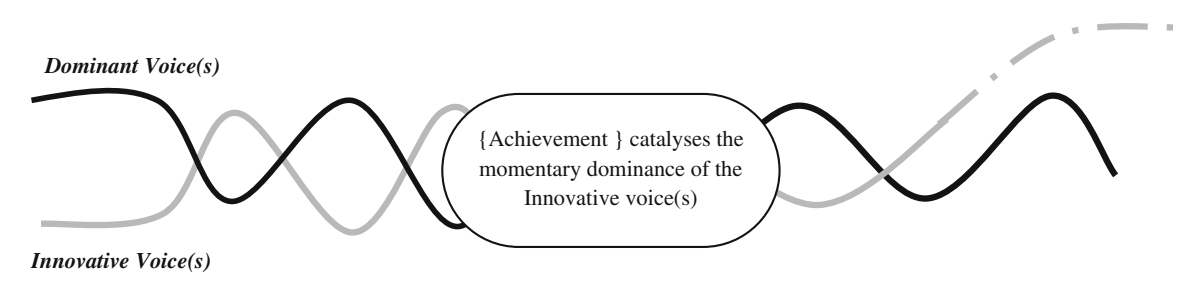

Time

Fig. 9 Escalation of the innovative voice(s) thereby inhibiting the dominant voice

\section{Balance: Dominant and Innovative Voice(s) Negotiate and Engage in Joint} Action At the sixth session, a new protonarrative \{Balance\} emerged, through the contrast between the old - $\{$ Pessimism $\}$ - and the new-\{Optimism $\}$ and $\{$ Achievement , integrating characteristics from the previous ones. The following example shows a more balanced relationship between pessimism and optimism.

Sixth session

Caroline: I also believe that, sometimes, being pessimistic creates some kind of balance because if you are too optimistic, you start trusting yourself too much and you'll not try. So, I think something good about being pessimistic is not to create too many expectations regarding the future... not to create expectations and excessively believe in ourselves, which forbids us to make the effort to attain a task. Usually, if we trust too much in ourselves, we may be led to assume 'Oh, I'm not going to study, I can do it...' And a bit of fear is not harmful, either, it makes us work harder and do our utmost.

Therapist: The purpose is really that: see the advantages of optimism and the disadvantages of that extreme, as well...

Caroline: Right, try to find some sort of balance... [emergence of an IM\{Balance $\}$.

As we have stated, IMs focused on \{Optimism $\}$ were a mere opposition to the problem, facilitating the return to it. Inversely, \{Balance\} opens up room for negotiation between the dominant and the innovative voice(s) (see Fig. 10). In this IM, the opposite voices appeared to be respectfully listening to one another by building a meaning bridge (Brinegar et al. 2006). A meaning bridge is a sign (a word, phrase, story, theory, image, gesture, or other expression) that represents the same meaning for the dominant and non-dominant voices. In this case, the protonarrative \{Balance\} connects pessimism and optimism, allowing the two poles to communicate with one another and engage in joint action. This meaning bridge thus allows both pessimism and optimism to serve as resources.

\section{Final Remarks}

Individuals constantly construct meanings through auto- and hetero-dialogues as a preadaptation mechanism, orienting themselves toward the immediately potential future, 


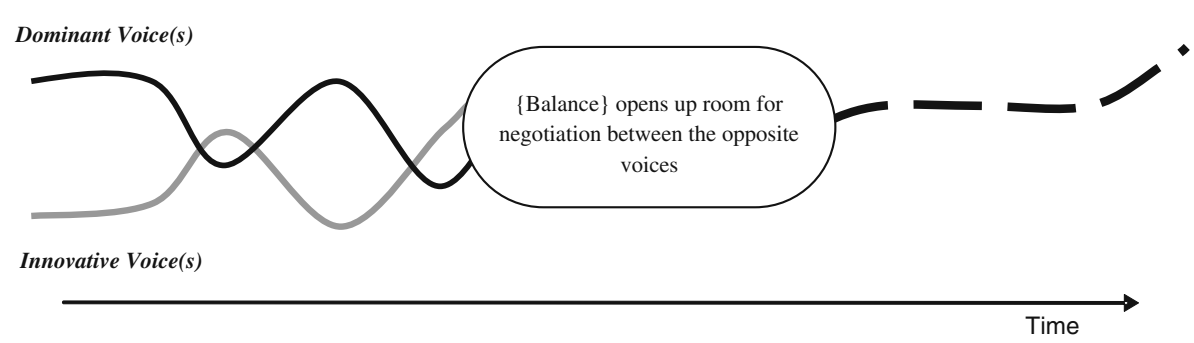

Fig. 10 Dominant and innovative voices negotiate and engage in joint action

reducing its uncertainty and unpredictability and mediating the relation with the surrounding world (Josephs and Valsiner 1998; Valsiner 2002). Moreover, "uncertainty challenges our potential for innovation and creativity to the utmost" (Hermans and Dimaggio 2007, p.10). Along these lines, life events or contexts which challenge the client's usual way of constructing meaning, such as a new dialogical encounter with a therapist, foster self-innovation or development (Cunha 2007). Obviously, these processes of innovation and development also occur in life outside therapy, but therapy offers a natural laboratory where often changes occur at a faster pace.

Either way, inside or outside therapy, change creates uncertainty, given that the past forms of adaptation are in a sense compromised (Kelly 1955), making the future less predictable. Thus, even when change is desired (Arkowitz and Engle 2007), if the degree of associated uncertainty is too threatening for the person, a "defensive and monological closure of the self and the unjustified dominance of some voices over others" (p. 10) could occur, since it challenges the feeling of quasi stability which people seek to maintain (Molina and del Río 2008).

In this paper we explored a specific way the dialogical self protects itself from uncertainty - the mutual in-feeding process between innovative voices (expressed in IMs) and dominant ones (expressed in the problematic self-narrative). The semioticdialogical approach enabled us to study the rapid flow of micro-processes that were involved in mutual in-feeding maintenance and transformation throughout Caroline's therapeutic process. The evolution of Caroline's case from meaning maintenance to meaning transformation seemed dependent on the semiotic regulated dialogical interchanges between the dominant voice(s) and the innovative one(s).

Initially, IMs focused on Optimism protonarrative were a mere opposition to the dominant self-narrative (Pessimism) and thus facilitated a mutual in-feeding relation between the dominant and the innovative voices. The resolution of mutual in-feeding seems to be promoted by the emergence of the Achievement protonarrative, which allowed an escalation of the innovative voice(s). Then Balance protonarrative led to an integration of both dominant and innovative voices to form an alternative selfnarrative, making the opposition, as in mutual in-feeding, virtually impossible.

Indeed, Balance protonarrative became a source of flexibility in dialogical self insofar as it appeared to enable a conditional dynamic movement between the previously opposing voices rather than a fixation on one of them (J. Valsiner, personal communication December 16, 2008). This is akin to "the absence of identification with any particular subject position" that characterizes Bakhtin's novelist (in a polyphonic novel) and "which implies freedom from the compulsion to construe the world from a perspective only" (Michel and Wortham 2002, pp. 11-12). 
The analysis of Caroline's case which initiates a line of intensive qualitative research into how return to the problem can turn into therapeutic movement that is, how the relation between innovative voices and the dominant voices evolve from mutual in-feeding to another form of dialogical relation. We identified two forms of solving the mutual in-feeding process: (1) escalation of the innovative voice(s) thereby inhibiting the dominant voice and (2) negotiating and engaging in joint action. In the future, it is our aim to explore if these processes emerge in different cases, as well as in non-therapeutic change.

Furthermore, the role of the therapist in turning mutual in-feeding into a therapeutic movement still needs to be studied in detail (see Ribeiro, Ribeiro, Gonçalves, Horvath, \& Stiles 2010). Indeed, mutual in-feeding needs to be understood in the interpersonal context in which it occurs - the intersubjective field created in all interactions between the therapist and the client (Engle and Arkowitz 2008). According to Engle and Arkowitz (2008), "therapists can facilitate the resolution of resistant ambivalence by creating in-session exercises that increase awareness and integration of disowned aspects of the self' (p.393), in the context of a safe and accepting relationship.

Acknowledgments This article was supported by Portuguese Foundation for Science and Technology Grants PTDC/PSI/72846/2006 (Narrative Processes in Psychotherapy, 2007_2010) and PhD Grants SFRH/BD/46189/2008 and SFRH/BD/48266/2008. We gratefully acknowledge the contribution of Jaan Valsiner, who critiqued earlier drafts of this article and assisted in the development of the concepts present herein, and extend our thanks to Eugénia Ribeiro and Joana Senra for allowing us to analyze the videos of Caroline's case.

\section{References}

American Psychiatric Association. (1994). Diagnostic and statistical manual of mental disorders (4th ed.). Washington, DC: American Psychiatric Association.

Arkowitz, H., \& Engle, D. (2007). Understanding and working with resistant ambivalence in psychotherapy. In S. G. Hofmann \& J. Weinberg (Eds.), The art and science of psychotherapy (pp. 171-190). New York: Routledge.

Bakhtin, M. M. (1981). The dialogic imagination: Four essays by M. M. Bakhtin (C. Emerson \& M. Holquist, Trans.). Austin: University of Texas Press.

Beck, A. T. (1976). Cognitive therapy and emotional disorders. New York International Universities Press.

Brinegar, M. G., Salvi, L. M., Stiles, W. B., \& Greenberg, L. S. (2006). Building a meaning bridge: Therapeutic progress from problem formulation to understanding. Journal of Counseling Psychology, $53,165-180$.

Cunha, C. (2007). Processos dialógicos de auto-organização e mudança: um estudo microgenético. [Dialogical processes of self-organization and change: a microgenetic study]. University of Minho: Unpublished master dissertation.

Engle, D., \& Arkowitz, H. (2008). Viewing resistance as ambivalence: Integrative strategies for working with resistant ambivalence. Journal of Humanistic Psychology, 48, 389-412.

Fernandes, E. (2007). When what I wish makes me worse... to make the coherence flexible. Psychology and Psychotherapy: Theory, Research and Practice, 80, 165-180.

Fernandes, E., Senra, J., \& Feixas, G. (2009). Terapia construtivista centrada em dilemas implicativos [Constructivist psychotherapy focused on implicative dilemmas]. Braga: Psiquilíbrios.

Flynn, E., Pine, K., \& Lewis, C. (2007). Using the microgenetic method to investigate cognitive development: an introduction. Infant and Child Development, 16, 1-6.

Goncalves, M., \& Guilfoyle, M. (2006). Dialogism and psychotherapy: therapists' and clients' beliefs supporting monologism. Journal of Constructivist Psychology, 19(3), 251-271. 
Gonçalves, M. M., Matos, M., \& Santos, A. (2009). Narrative therapy and the nature of "innovative moments" in the construction of change. Journal of Constructivist Psychology, 22, 1-23.

Gonçalves, M. M., \& Ribeiro, A. P. (2010). Narrative processes of innovation and stability within the dialogical self. In H. J. M. Hermans \& T. Gieser (Eds.), Handbook of dialogical self. Cambridge: Cambridge University Press.

Gonçalves, M. M., Ribeiro, A. P., Matos, M., Mendes, I., \& Santos, A. (2010a). The innovative moments coding system: A coding procedure for tracking changes in psychotherapy. In S. Salvatore, J. Valsiner, J. T. Simon, \& A. Gennaro (Eds.), YIS: Yearbook of idiographic science, volume 2 (pp. 107-130). Rome: Firera \& Liuzo.

Gonçalves, M. M., Ribeiro, A. P., Matos, M., Mendes, I., \& Santos, A. (2010b). Tracking novelties in psychotherapy research process: The innovative moment coding system. Manuscript in preparation.

Gonçalves, M. M., Santos, A., Salgado, J., Matos, M., Mendes, I., Ribeiro, A. P., et al. (2010c). Innovations in psychotherapy: Tracking the narrative construction of change. In J. D. Raskin, S. K. Bridges, \& R. Neimeyer (Eds.), Studies in meaning 4: Constructivist perspectives on theory, practice, and social justice (pp. 29-64). New York: Pace University Press.

Gonçalves, M. M., Ribeiro, A. P., Stiles, W. B., Conde, T., Matos, M., Martins, C., et al. (2010d). The role of mutual in-feeding in maintaining problematic self-narratives: exploring one path to therapeutic failure. Psychotherapy Research. doi:10.1080/10503307.2010.507789.

Gustafson, J. P. (1992). Self-delight in a harsh world. New York: Norton.

Hermans, H. J. (1996a). Opposites in a dialogical self: constructs as characters. Journal of Constructivist Psychology, 9, 1-26.

Hermans, H. J. M. (1996b). Voicing the self: from information processing to dialogical interchange. Psychological Bulletin, 119, 31-50.

Hermans, H. J. M. (2001). The dialogical self: toward a theory of personal and cultural positioning. Culture \& Psychology, 7, 243-281.

Hermans, H. J. M., \& Dimaggio, G. (Eds.). (2004). The dialogical self in psychotherapy: An introduction. New York: Brunner-Routledge.

Hermans, H. J. M. \& Dimaggio, G. (2007). Self, identity, and globalization in times of uncertainty: A dialogical analysis. Review of General Psychology, 11, 31-61.

Hermans, H. J. M., \& Hermans-Jansen, E. (1995). Self-narratives: The construction of meaning in psychotherapy. New York: Guilford.

Hermans, H. J. M., \& Hermans-Konopka, A. (2010). Dialogical self theory. Positioning and counterpositioning in a globalizing society. Cambridge: Cambridge University Press.

Hill, C. A., Knox, S., Thompson, B. J., Nutt Williams, E., Hess, S. A., \& Ladany, N. (2005). Consensual qualitative research: an update. Journal of Counseling Psycholog, 52(2), 196-205.

Jacobson, N. S., \& Truax, P. (1991). Clinical significance: a statistical approach to defining meaningful change in psychotherapy research. Journal of Consulting and Clinical Psychology, 59, $12-19$.

Josephs, I., \& Valsiner, J. (1998). How does autodialogue work? Miracles of meaning maintenance and circumvention strategies. Social Psychology Quarterly, 61, 68-83.

Josephs, I., Valsiner, J., \& Surgan, S. E. (1999). The process of meaning construction-dissecting the flow of semiotic activity. In J. Brandstadter \& R. M. Lerner (Eds.), Action and development. Theory and research through the life span. London: Sage Publications.

Kelly, G. A. (1955). The psychology of personal constructs. New York: Norton.

Lambert, M. J., Burlingame, G. M., Umphress, V., Hansen, N. B., Vermeersch, D. A., Clouse, G. C., et al. (1996). The reliability and validity of the Outcome Questionnaire. Clinical Psychology \& Psychotherapy, 3, 249-258.

Lamey, A., Hollenstein, T., Lewis, M. D., \& Granic, I. (2004). GridWare (Version 1.1). [Computer software]. http://statespacegrids.org.

Leiman, M. (2002). Toward semiotic dialogism: the role of sign mediation in the dialogical self. Theory \& Psychology, 12, 221-235.

Machado, P. P. P., \& Klein, J. (2006). Outcome Questionraire-45: Portuguese psychometric data with a non-clinical sample. Poster presented at the 37th Annual Meeting of the Society for Psychotherapy Research. Edinburgh, Scotland.

Machado, P. P. P., \& Fassnacht, D. (2010). The Outcome Questionnaire (OQ-45) in a Portuguese Population: Psychometric Properties, ANOVAS, and Confirmatory Factor Analysis.

Mandler, J. (1984). Scripts, stories, and scenes: Aspects of schema theory. Hillsdale: Erlbaum.

McGlinchey, J. B., Atkins, D. C., \& Jacobson, N. S. (2002). Clinical significance methods: which one to use and how useful are they? Behavior Therapy, 33, 529-550. 
Michel, A., \& Wortham, S. (2002). Clearing away the self. Theory and Psychology, 12, 625-650.

Molina, M. E., \& del Río, M. T. (2008). Voices of the self as therapeutic resources (commentary on Morioka). International Journal for Dialogical Science, 3(1), 131-142.

Neimeyer, R. A., Herrero, O., \& Botella, L. (2006). Chaos to coherence: psychotherapeutic integration of traumatic loss. Journal of Constructivist Psychology, 19, 127-145.

Ribeiro, A. P., \& Gonçalves, M. M. (2010). Innovation and stability within the dialogical self: the centrality of ambivalence. Culture \& Psychology, 16(1), 116-126.

Ribeiro, A. P., Gonçalves, M. M., \& Ribeiro, E. (2009). Processos narrativos de mudança em psicoterapia: Estudo de um caso de sucesso de terapia construtivista [Narrative change in psychotherapy: A goodoutcome case of construstivist therapy]. Psychologica, 50, 181-203.

Ribeiro, E., Ribeiro, A. P., Gonçalves, M. M., Horvath, A. O., \& Stiles, W. B. (2010). How collaboration in therapy becomes therapeutic: Therapeutic Collaboration Coding System. Manuscript in preparation.

Ribeiro, A. P., Bento, T., Gonçalves, M. M., \& Salgado, J. (2010a). Self-narrative reconstruction in psychotherapy: looking at different levels of narrative development. Culture \& Psychology, 16(2), 195-212.

Ribeiro, A. P., Bento, T., Salgado, J., Stiles, W. B., \& Gonçalves, M. M. (2010b). A dynamic look at narrative change in psychotherapy: A case study tracking innovative moments and protonarratives using state space grids. Psychotherapy Research. doi:10.1080/10503307.2010.504241.

Ribeiro, A. P., Gonçalves, M. M., \& Santos, A. (2010c). Innovative moments in psychotherapy: From the narrative outputs to the semiotic-dialogical processes. In S. Salvatore, J. Valsiner, S. Strout, \& J. Clegg (Eds.), YIS: Yearbook of idiographic science 2010 - Volume 3. Rome: Firera Publishing Group.

Salgado, J., \& Gonçalves, M. M. (2007). The dialogical self: Social, personal, and (Un)conscious. In J. Valsiner \& A. Rosa (Eds.), The Cambridge handbook of sociocultural psychology (pp. 608-621). Cambridge: Cambridge University Press.

Salgado, J., \& Hermans, H. J. M. (2005). The return of subjectivity: from a multiplicity of selves to the dialogical self. Electronic Journal of Applied Psychology, 1, 3-13.

Santos, A., \& Gonçalves, M. M. (2009). Innovative moments and change processes in psychotherapy: An exercise in new methodology. In J. Valsiner, P. C. M. Molenaar, M. C. D. P. Lyra, \& N. Chaudhary (Eds.), Dynamic process methodology in the social and developmental sciences (pp. 493-526). New York: Springer.

Santos, A., Gonçalves, M. M., \& Matos, M. (2010). Innovative moments and poor-outcome in narrative therapy. Counselling and Psychotherapy Research. Advance online publication doi:10.1080/ 14733140903398153.

Sato, T., Hidaka, T., \& Fukuda, M. (2009). Depicting the dynamics of living the life: The Trajectory equifinality model. In J. Valsiner, P. Molenaar, M. Lyra, \& N. Chaudhary (Eds.), Dynamic process methodology in the social and developmental sciences (pp. 217-240). New York: Springer.

Senra, J., Ribeiro, E. (2009). The process of change in implicative dilemmas: The case of Rose. Manuscript in preparation.

Senra, J., Feixas, G., \& Fernandes, E. (2007). Manual de Intervención en Dilemas Implicativos. [Manual of intervention in implicative dilemmas]. Revista de Psicoterapia, 63/64, 179-201.

Siegler, R., \& Crowley, K. (1991). The microgenetic method: a direct for studying cognitive development. The American Psychologist, 46, 606-620.

Stiles, W. B. (1999). Signs and voices in psychotherapy. Psychotherapy Research, 9, 1-21.

Stiles, W. B. (2002). Assimilation of problematic experiences. In J. C. Norcross (Ed.), Psychotherapy relationships that work: Therapist contributions and responsiveness to patients (pp. 357-365). New York: Oxford University Press.

Stiles, W. B. (2005). Case studies. In J. C. Norcross, L. E. Beutler, \& R. F. Levant (Eds.), Evidence-based practices in mental health: Debate and dialogue on the fundamental questions (pp. 57-64). Washington, DC: American Psychological Association.

Stiles, W. B. (2009). Logical operations in theory-building case studies. Pragmatic Case Studies in Psychotherapy, 5, 9-22.

Stiles, W. B., Osatuke, K., Glick, M. J., \& Mackay, H. C. (2004). Encounters between internal voices generate emotion: An elaboration of the assimilation model. In H. H. Hermans \& G. Dimaggio (Eds.), The dialogical self in psychotherapy (pp. 91-107). New York: Brunner-Routledge.

Valsiner, J. (2002). Forms of dialogical relations and semiotic autoregulation within the self. Theory and Psychology, 12, 251-265.

Valsiner, J. (2004). Temporal integration of stuctures within Dialogical Self. Keynote lecture at the 3rd International Conference on the Dialogical Self, Warsaw. 
Valsiner, J. (2008). Constraining one's self within the fluid social worlds. Paper presented at the 20th Biennial ISSBD meeting, Würzburg.

Valsiner, J., \& Sato, T. (2006). Historically structured sampling (HSS): How can psychology's methodology become tuned into the reality of the historical nature of cultural psychology? In J. Straub, C. Kölbl, D. Weidemann, \& B. Zielke (Eds.), Pursuit of meaning: Theoretical and methodological advances in cultural and cross-cultural psychology (pp. 215-251). Bielefeld: transcript Verlag.

António P. Ribeiro, MA is a student of the PhD Program in Clinical Psychology at University of Minho (Braga, Portugal) with a PhD scholarship from the Fundação para a Ciência e Tecnologia (FCTPortuguese Foundation for Science and Technology: reference SFRH/BD/46189/2008). His current research interests are theoretically focused in narrative and dialogical perspectives and their application to change processes in psychotherapy. ADDRESS: António P. Ribeiro, University of Minho, Portugal, School of Psychology, Campus de Gualtar, Braga, P-4700. [email: id2218@alunos.uminho.pt]

Miguel M. Gonçalves, PhD is Professor at the School of Psychology in University of Minho (Braga, Portugal). He has been interested in dialogical and narrative studies of the self and in narrative psychotherapy. He is presently developing a research program on the role that narrative innovations play in the promotion of psychotherapeutic change. ADDRESS: Miguel M. Gonçalves, University of Minho, Portugal, School of Psychology, Campus de Gualtar, Braga, P-4700, Portugal. [email: mgoncalves@psi.uminho.pt] 